Open Access

\title{
Contemplative pedagogy: a descriptive account of two approaches to student engagement at Loyola Marymount University
}

\author{
Jane Brucker and Christopher Key Chapple*
}

\author{
* Correspondence: \\ cchapple@lmu.edu \\ Loyola Marymount University, Los \\ Angeles, USA
}

\begin{abstract}
In this article the alternating voices of colleagues and collaborators Jane Brucker and Christopher Chapple describe their way of using contemplative pedagogies to bring Engaged Learning to their students at Loyola Marymount University. A requirement of the curriculum for all undergraduate students, these courses integrate study and reflection beyond the classroom. As a professor of studio arts, Brucker has developed techniques of awareness that utilize a contemplative approach with students engaged in drawing and creative activity in a studio or off-campus setting. As a professor of comparative theology, Chapple has designed course requirements for meditation experience and field visits that embed his students within the contemplative aspects of Buddhism as well as in communities deeply grounded in environmental action. Grounded in the Jesuit-Marymount concern for educating the 'whole person', Brucker and Chapple understand this as engaging students in experiences that include the relationship between the inner experience of meditation and the outward experiences of spirituality, creativity, and nature.
\end{abstract}

Keywords: Contemplative studies, Contemplative pedagogy, Creative pedagogy, Buddhism, Meditation, Engaged learning, Environment

\section{LMU's tradition and commitment to student engagement}

Jane Brucker and Chris Chapple have taught for many years at Loyola Marymount University. Chris started in 1985 and Jane in 1993, both finding fundamental inspiration for their teaching from the combined heritage of the Jesuits, the Marymount Sisters, and the Sisters of St. Joseph of Orange. With roots in the spiritual humanism of the earliest Jesuit colleges, LMU's pedagogical tradition has an abiding concern for the education of the whole person, interpreted in the university's mission as "a simultaneous process of information, formation, and transformation that encourages personal integration of the student's thinking, feeling, choosing, evolving self' [LMU (2016) website]. In this descriptive account, Brucker and Chapple will demonstrate how they each combine LMU's mission to educate the whole person with LMU's Engaged Learning philosophy and contemplative pedagogy.

(c) The Author(s). 2017 Open Access This article is distributed under the terms of the Creative Commons Attribution 4.0 International License (http://creativecommons.org/licenses/by/4.0/), which permits unrestricted use, distribution, and reproduction in any medium, provided you give appropriate credit to the original author(s) and the source, provide a link to the Creative Commons license, and indicate if changes were made. 
According to LMU, Engaged Learning is comprised of "experiential opportunities with academic preparation" and "active hands-on learning, critical reflection, and the integration of experience with knowledge" [Bellarmine College (2016) website]. The concern for Engaged Learning stems from the contemplative foundation of Jesuit education that started with the work of Ignatius of Loyola (1491-1556), who, as a leading figure of the counter-reformation, sought to redefine and expand the reach of education. Along with attention to basic skills, Ignatius developed a system of contemplative practice that informs the work of the many institutions he inspired. Randy Roche, S.J., Director of LMU's Center for Ignatian Spirituality, emphasizes that contemplation, as part of the Ignatian tradition, is accessible to all persons, noting that it is does not require religious faith. Additionally, contemplation is used to "more fully engage reality," to allow students to engage in any activity more fully and is an important part of discernment. Contemplation engages all the faculties of our minds and hearts through the processes of "remembering, reflecting, thinking, and imagining" (Roche 2016).

\section{Engaged learning and contemplative practice within two disciplines Brucker:}

Because many artists throughout history have used contemplative practice as an integral part of their creative process, it is surprising that few, if any, studio arts curricula use contemplation as a part of their teaching methodology. Traditionally, there has been a focus on teaching technical development, resulting in an emphasis on the outcome of student work rather than the development of reflective student awareness and understanding of the internal creative process. Integrating contemplative practice into arts teaching can set the tone for in-depth problem-solving and the kind of slowing down that promotes visual understanding.

In my classes, I use Engaged Learning principles inside and outside of the studio environment to teach students how to use contemplative practices such as breath, movement, or visualization to generate a more authentic approach to art-making and sketchbook/journal writing and drawing exercises. In the dialogue that follows, I use examples from my courses within a studio arts curriculum or from my freshman seminar in contemplative arts.

\section{Chapple:}

Contemplation grounds the origins of the religions of Asia, arising from the Upanișads, Yoga practice, and Buddhist meditation. In addition to understanding history and key principles, it has become possible for students in my theology classes to access highly trained teachers in contemplative method, both on and off campus. My undergraduate courses for the past few years have been Buddhism in the fall and World Religions and Ecology in the spring. Attuned to LMU's mission, each has been developed with aspects of contemplative engagement.

Los Angeles provides a tapestry of learning opportunities for our students. As a requirement of the Buddhism course, students immerse themselves in a tradition of meditation for three extended sessions of more than an hour each. These first of three meditation experiences allow students to become familiar with the basic technique, whether Vipassana or Zen. The second one allows them to settle into the practice. The 
third provides an opportunity to refine the hard work of keeping still. By putting their bodies, breath, and mind into a place of focus, they enter into the world of contemplative practice.

They also visit a Buddhist temple or meditation center and write and reflect on this experience. These community resources come in many forms, including centers for Vietnamese, Sri Lankan, Chinese, Japanese and other immigrant communities, as well as what might be characterized as centers of American Buddhism. Because they are already familiar with basic teachings and meditation practices, they are able to engage from a place of understanding.

In another course titled World Religions and Ecology students learn the Big History of their immediate vicinity, with the university atop a mesa overlooking a marshland and the Pacific Ocean beyond. Big History urges that all educational experiences begin with a recognition of the 13.7 billion year history of the universe, the 4 billion year history of planet Earth, and the geology and natural history of one's immediate bioregion. Hiking and learning some of the native plants and the stories of the original inhabitants evokes a reflective mood in the students that is focused on the locality in which they are undertaking contemplative practice.

\section{Two ways to begin}

\section{Brucker:}

Beginning a class with a meditation is a way to help students transition from their busy, media-filled days and introduces quiet and internal focus. A breath or movement meditation is used during each class session to slow the observation process down so that students can observe their total experience. It prepares students to be present to the writing, drawing and seeing exercises I introduce, and to be present to their own particular experience of the day. From a contemplative viewpoint this can mean attending specifically to one's bodily experience and its relationship to reflection and activity. In a studio exercise it may mean awareness of visual sensory input, tension, proprioception, inner stillness, or the observation of thought and movement.

For example, on the first day of the freshman seminar each student is asked to sit comfortably supported by their chair. With their eyes closed they are asked to become aware of their feet on the floor, their breath, the sensation of air moving through the room, the rough or smooth fabric of their clothing as they touch the surface of their jeans, or instead to hold the hem of their shirt. Once they have settled into the meditation, I ask them to attend to their breath more intently. I ask them to notice the movement in the torso as the breath moves in and out, visualize the diaphragm as it encourages air flow, and consciously take a deep breath noticing how the rhythm of the breath returns to normal. Students are prompted to use their sensory capacities to feel the temperature of the air or observe the nostrils or the mouth as the air passes in and out. At the same time, I introduce the idea of awareness, asking them to refrain from judgment and distraction. Instead I encourage daydreaming about the breath, wondering about how it sounds or waiting for ideas that might emerge from their imagination. Sven Birkerts in his book, Changing the Subject: Art and Attention in the Age of the Internet (Birkerts 2015), describes distraction as "shearing away from focus" while daydreaming is honored as "the very emblem of the soul's freedom". He compares the 
two by defining distraction as "a lowering of intensity" in contrast to daydreaming where, "the word itself conveys immersed intensity" bringing it "closer to our experience of art" (Birkerts 2015, 248).

If possible this meditation can stretch from 10 to 30 minutes depending on signs of the students' focus. I observe the students in the exercise and look for quiet stillness and peaceful ease in their postures as well as their responsiveness to my verbal cues and guidance. When the exercise is complete, they immediately write and draw responsively in their sketchbook/journals. We then together read Jon Kabat-Zinn's short chapter on Keeping the Breath in Mind from Wherever You Go, There You Are (Kabat-Zinn 1994, 18-19). As homework, these visual and written reflections are crafted into a more refined response using a piece of paper cut to 18 inches square and using only line drawing and pencil.

During the next class, the same students engage in a parallel meditation when I ask them to consider walking up and down the large outdoor staircase just outside of the studio. Students begin by reading together Kabat-Zinn's chapter Going Up Stairs (Kabat-Zinn 1994). In this chapter, he describes his own experience of feeling, "frequently pulled by my need to be somewhere else" and challenges this pull by asking, "why does your response time have to be so fast that it pulls you out of the life you were living in the preceding moment" (Kabat-Zinn 1994, 201-203). Like Kabat-Zinn, I ask them to consider if their transition between steps could be more graceful, whether they can pause to look around them, and to notice where their torso is in relation to their head, legs and feet as they step up or down. They then are divided up and asked to watch other students as they ascend and descend the numerous staircases around the building. Again students return to writing and drawing notes in their sketchbook/journals with the direction to refine their descriptive response using a piece of paper cut to 18 inches square and using only line drawing and pencil.

Both exercises focus on experience and observation, encouraging students to notice moments that might otherwise pass without reflection.

\section{Chapple:}

At various times during the semester we engage in guided meditations in class including mindfulness of the body and breath as taught in the Satipatthana Sutta. Our textual engagement and reflection requires a hermeneutic of self introspection, a linking of one's own story to the life of Siddhartha Gautama, who became the Buddha. The life of the Buddha and the foundational teachings that he conveyed carry resonances with the students who are invited to existentially engage the four noble truths of the universality of pain, its origins in craving, the possibility of release, and the path toward purification (duhkha, trsna, nirodha, marga) and his no-self assessment of the human condition. Understanding these core philosophical and psychological teachings prepares the students for their practical encounters with meditation and their temple visits.

Students read and discuss primary texts, are assigned to partake in three meditation sessions, and they learn the early teachings of the Theravada School as practiced in Sri Lanka, Myanmar, Thailand, Laos, and Cambodia. They also study Mahayana Buddhism, which flourishes in China, Korea, and Japan, and Vajrayana Buddhism, found primarily in Tibet.

The three meditation sessions include direct instruction in two different forms of meditation. Three of the six groups of four participate in the early morning Zen sitting 
group which meets on Mondays and Wednesdays from 7:30 to 9 a.m. The instructor, a professor of ethnomusicology, has trained in Rinzai Zen at the Rinzai-ji Zen Center in Los Angeles for 40 years and remains an active and engaged member of that community. He begins each sitting with a brief overview of the practice, including instruction on how to focus the mind by keeping the eyes open and counting the breath. Cushions are provided. After twenty minutes of silent meditation, all participants engage in a ten-minute period of walking meditation, followed with another twenty minutes of silent sitting. The instructor gives a brief dharma talk at the end of the session, and allows for questions and answers.

The rest of the student groups participate in a Theravada practice. The Vipassana Buddhist meditation group meets on Tuesday nights from 7:30 to 9:30 p.m. The instructor also teaches in the Mindful USC program at the University of Southern California. She has been practicing meditation for more than 40 years and participates in twice-yearly ten day retreats in the Theravada tradition. Students are welcomed into the space, given basic meditation instruction, and enter a period of silence for 35 minutes, focusing on the body, the breath, and, on occasion, following guidance into a practice such as compassion or loving kindness. The instructor meets with all new students for ten minutes while the others either do silent walking meditation or socialize. The group then reconvenes for a Dharma talk of fifteen or twenty minutes, followed with discussion.

Students assigned to the Theravada practice of Vipassana explore the book Wide Awake by Diana Winston. She describes mindfulness meditation as "a quality of mind that stays connected and aware of whatever is happening"(Winston 2003, 72), a useful tool for any student. The students who practice Zen and visit one of Los Angeles' many Mahayana temples read Training in Compassion: Zen Teachings on the Practice of Lojong by Zen Master Norman Fischer. Fischer writes that "the practice of mind training begins with the effort to turn toward difficulty rather than away from it. When we are no longer daunted by difficulties but are willing to engage and make use of them, we become truly resilient individuals" (Fischer 2013, 19). This advice speaks to the life condition of the student as well as to the challenge of calming the mind in meditation.

\section{Observation and integration}

Brucker:

Deepening awareness can be taught. In the freshmen seminar, during a later class session, I repeat the breath awareness exercise I discussed earlier and then ask students to close their eyes while I put a small unknown object into their non-dominant hand. They are asked to feel the object with their fingers, resisting the mind's anxious desire to 'name' the object. Instead I ask them to reflect descriptively on their experience of the object. What are the edges like? How might they explore all sides of the object? Is the object smooth, rough, irregular, or round? Without looking at the object, I ask the students to open their eyes and begin writing in their journal/sketchbooks about the object they are holding. When writing, students are inspired to pay attention to their full experience as if seeing through their sense of touch, marveling at it, and describing what they see while bypassing their need to identify and name. Writer Natalie Goldberg describes this experience as a transformative moment when "there is no writer, no paper, no pen, no thoughts. Only writing does writing - everything else is gone" (Goldberg 1986, 16). 
A related awareness exercise called 'Blind Line' can be used with beginning studio arts students. Drawing teacher Kimon Nicolaides introduced this technique in 1941, in his book The Natural Way to Draw, believing it involved a sense of both sight and touch (Nicolaides 1941). Art educator Betty Edwards expands on the technique when she suggests this method improves drawing ability because it forces us into a purely spatial mode of observation. Because we cannot see our pencil, we are not influenced by preconceived ideas about drawing or about the image we are recording (Edwards 1979, 12-18).

In this exercise, students begin by focusing their eye on some point, anywhere on the form and without taking their eyes off of the form, convince themselves that the pencil is actually touching that point on which the eye is fastened. Movement is coordinated so that the eye and pencil trace the edge of the form slowly along the outer contour lines and follow along lines that wind into the interior of the form. Students complete the exercise with an intensity of focus that also demands they inhibit their habit of looking at the paper and judging what they see. There is a great temptation to look down at the paper! Using the contemplative method of 'Blind Line' allows my students to see whatever happens to be in front of them - a leaf, a tea cup, a shell - in new ways and produces interesting results when they capture that object using only line. In time it is clear to them that concentrating only on the quality and intensity of the line they are seeing and drawing allows them to become engaged with what artist and author Frederick Franck calls the 'pure' act of seeing without judging or labeling the object they observe. Franck prompts his students to look beyond naming the object, saying, "quickly we stick labels on all that is, labels that stick once and for all. By these labels we recognize everything but no longer see anything. We know the labels on all the bottles, but never taste the wine" (Franck 1973, 3-4).

A proponent of this technique as a spiritual exercise, Franck notes that time seems suspended in what he describes as experiences of intense 'seeing' and drawing that invokes a connection to the earth and a sense of one-ness with all of the created world. As their skill with the technique increases, I take students outdoors in the garden to find their subjects. Nothing is too small, too simple, or too subtle to become the subject of their drawn or written response. In his book The Zen of Seeing: Seeing/Drawing as Meditation, Franck (1973) describes philosophically the many Zen moments that accompany the activity of drawing using his own sensitively beautiful pen-and-ink drawings. Pedagogically, Franck believes we are all creative and that drawing/seeing is a meditative activity that anyone can enjoy. A sketchbook and drawing tool are all that is needed to discover that we are one with what we see, and that we only truly see by quieting the mind, and softening the gaze (Franck 1973).

\section{Slow time \\ Chapple:}

The teaching of Buddhism at LMU historically has integrated with on-campus activities which have included the creation and destruction of a Tibetan sand mandala (2001) and a full morning, all campus meditation with Venerable Thich Nhat Hanh, the Vietnamese Zen master who helped negotiate the end of the Vietnam war (2011). These events captivated the attention of students as they witnessed the patient creation of the sand mandala and meditated and chanted in the company of Thich Nhat Hanh. 
More recently, the Buddhism course linked with the college-wide Slow Time theme of the 2016-2017 Bellarmine Forum. Each year LMU's Bellarmine College of Liberal Arts explores a theme of common concern on topics that have included environmentalism, globalization, and social justice. The Slow Time initiative gathered select classes in Philosophy, English, History, Film Studies, and Theology, supporting small and large faculty conversations and presentations, often in conjunction with the Center for Teaching Excellence. A special archival exhibit was mounted by the library, a labyrinth was created on the campus bluff overlooking the Pacific Ocean and the Santa Monica Mountains, and a cairn-building complex was established in the fine arts quad.

The Slow Time students, as well as all incoming first year students, read A Tale for the Time Being, written by Ruth Ozeki (2013), a long time student of Zen meditation. This novel gives a central role to Jizo, an elderly Buddhist nun who helps the young protagonist sort out her difficulties of being bullied in Tokyo after spending a few years with her family in America. The author and her Zen master, Roshi Norman Fischer, visited with the class on separate occasions, giving the students direct access to the creative process that, in this case, links contemplative practice with the craft of writing.

Just prior to the arrival of Roshi Fischer, the students engaged in a twenty-minute group silent walking meditation. It was quite a group, numbering approximately 100 students and professors from the four combined classes. They alternately focused on the rhythm of their gait and breath, punctuated by occasional gazing out the wall of windows to the eucalyptus trees and to the horizon line where the sky meets the Pacific Ocean and the Santa Monica Mountains. Once established in a place of timeless presence, Roshi Fischer discussed the notion of time from Dogen's Shobogenzo, a portion of the text that plays a key role in the Ozeki novel:

For the time being, standing on the tallest mountaintop,

For the time being, moving on the deepest ocean floor,

For the time being, a demon with three heads and eight arms...

For the time being, a pillar or a lantern,

For the time being, any Dick or Jane,

For the time being, the entire earth and the boundless sky (Ozeki 2013, 1).

Ozeki's translation turns time into the present moment, while acknowledging its omni-presence and ubiquity.

In preparation for Ruth Ozeki's visit, the students were asked to generate questions. This required recollecting their reading of the book and what they had learned so far about Buddhism. The questions demonstrated their inquisitiveness about the creative impulse and the contemplative process:

- What is the connection between Ruth the character and Ruth the writer?

- Is this work fiction? Autobiography?

- How does Nao's relationship to femininity relate to wisdom in Buddhism?

- What were the inspirations and motivations for writing this book?

- Is Ruth Ozeki "Ruth" or "Nao" (the Japanese school girl) or "Jiko" (Nao's great grandmother the Buddhist nun)? 
- As a Japanese American, what are your ideas on contemporary Japanese culture \& American culture?

- How did you get to know Norman Fischer? Discover Buddhism?

- Do you have a supa powa? (Japanese pronunciation of the Super Power that Nao developed due to the dissociative experience of being bullied.)

This final question generated laughs and also prompted a thoughtful reply from the author. She paused and stated that, yes, she has a super power in Zazen. She elaborated that through sitting she has gotten to know and understand her own mind, which gives her an utmost sense of power and grounding.

\section{Brucker:}

My freshmen seminar students also engaged with the Slow Time theme through several visits to 'The Displacement Garden' created by Los Angeles artist Richard Turner and LMU English professor Paul Harris in an unusual open cage-like structure within the art department's courtyard. The installation space is filled with flat smooth grey stones and asks students to take time to reflect on themes of displacement, home and the refugee crisis related to themes of movement and alienation connected to the freshman book by Ruth Ozeki (2013). In 'The Displacement Garden' my students were prompted to meditate on the dynamic tension between volumes and voids similar to sarensui (dry landscape) Zen rock gardens. They were invited to sit and gaze in peace or practice contemplative stone stacking [Harris (2016), web].

Students were asked to enter and walk through the space slowly, noticing how the space changes as you move through it. I used the opportunity the space provided to introduce the concept of proprioception to students. Proprioception is the sensory modality that allows us to know where our body parts are in space and in relation to each other. Choosing a stone to hold in one hand, students were asked to simply hold the stone behind their back and determine the position of the stone relative to their waist. Understanding the location of the stone (above or below the waist) is an example of proprioceptive knowing. They were then asked to continue to explore proprioception with their eyes closed, moving the stone, stretching it out in front of them or holding it above their head. I asked them again to become aware of their strong and accurate sense of the stone's location in relation to their body. Lastly, still with their eyes closed, I asked them to sense their whole body in relation to the garden space. Can they sense the air above them or the wall at their sides? Can they feel what is behind them and what the space in front of them is like? If they are sitting can they stand up with their eyes still closed? If they are standing can they take a step? To what extent is moving while the eyes are closed 'disorienting'? What emotions or feelings are connected with their experience?

Lastly, in this quiet plant-less garden, my students sit on simple concrete benches; carefully and deliberately stacking rocks into prayer stone stacks, or cairns, as a way of examining their experience of place and comfort. I introduce stone stacking as an ancient meditative practice linking material and spiritual dimensions. In some traditions, stone stacking is a form of worship, memorializing or expressing gratitude and as an aesthetic practice, my students study the artworks of Andy Goldsworthy. 
As an Engaged Learning experience, my students spent time inside and outside of class visiting 'The Displacement Garden' throughout the semester. Each time, they recorded the impact of the physical space on their bodies and minds by recording their experience using photography, writing and drawing in their sketchbook/journals.

\section{On the cushion, in the field Chapple:}

The Buddhism class forms six learning communities of four students each. Each group makes a presentation to the class and each student submits her or his own paper on the experience of performing meditation and participating in temple activities. Groups one, two, and three attend three Vipassanā sessions at LMU and visit/participate in an offsite experience either at two American Buddhist Centers that arose from the Burmese tradition, InsightLA, or Against the Stream. Or they can visit one of the many Theravāda Centers found in the region. They include material from the book Wide Awake: A Buddhist Guide for Teens, written by Diana Winston (2003) who trained in Burma and teaches mindfulness at UCLA. Groups four, five, and six participate in Zen sessions at LMU and participate in an offsite experience at the Zen Center of Los Angeles or one of the other Zen Centers in the region. They read and discuss the Norman Fischer book Compassion in Action: A Zen Perspective on Lojong Practice (2013). Fischer, true to the Slow Time theme, writes: “Don't go so fast. Mind training is not a race to the finish line.... Mind training is a practice of a lifetime-our lifetime will end soon enough, there is certainly no rush to bring that eventuality about... Don't go so fast is an invitation to know our impatience, our silly fixation on perfection and accomplishment, and when we do, to have a good laugh with ourselves and drop it. Literally to stop, take a breath, and let go" (Fischer 2013, 119).

The field trip and presentation project must include reflection on the student's experience of Engaged Learning. Students are urged to keep notes following each of the three meditation sessions. They also keep a journal of their visits to Buddhist temples or centers. Students are asked to present material from their own experiences and provide answers to the following questions:

What is the name and address of the organization? What aspects of Buddhism are represented? How old is the organization? Who were the founders? What are the primary teachings conveyed? How did the sermon or guided tour or ritual that you participated in reflect what you have learned in class (be specific)? Are the members of the congregation from the same ethnic background? What primary teachings were conveyed? How do the activities of the center/temple/sitting group reflect material you have learned in class or found in the readings? What impressed you most about this organization? Why do people attend? Would you return? If applicable, how is this different from your own experience of a religious organization? Is it the same? Be certain also to include your own thoughts on the field experiences. Were you anxious? Did you find the people friendly? Did you learn something about the culture? What were your responses to the experience?

Though students do not visit each of these in any given semester, their reports indicate a high level of engagement with their study of Buddhism, sometimes bordering on life-changing. For instance, many persons at Against the Stream are "in recovery" and 
tell harrowing stories of their path to sobriety. Students have leveled a trenchant critique at some who pick and choose what they like about Buddhism, suggesting that such cultural appropriation might be inappropriate. Others have expressed the thrill of rhythmic chanting at the Soka Gakkai Friendship Center, comfort at the acceptance they felt at the Zen Center of Los Angeles, and awe at the scope of the Hsi Lai Buddhist Temple, the largest in the western hemisphere. These experiences will remain with them far after graduation.

\section{Brucker:}

Students in my freshman seminar explore the role of movement in meditation during a walking meditation inspired by educational ecologist John Francis and his books The Ragged Edge of Silence: Finding Peace in a Noisy World (Francis 2011) and Planetwalker: 22 Years of Walking. 17 Years of Silence (Francis 2009). Students enjoy his engaging talk "The Power of Walking and Silence" on TED and research his work with the National Geographic Society (2012).

The walking experience begins at the studio and proceeds in a winding arc across the campus. We do this as a group in the beginning of class after reading and study of John Francis and previous work with silent sitting meditations. Students are prompted to experience this meditation as a time of silent reflection and awareness. Noticing the experience of the landscape, the walk begins with each student in a line about 3 feet apart. They do not carry anything with them but have their sketchbook/journals ready to create a 'map' drawn from memory upon returning to the classroom/studio. I intentionally lead them on a path that does not have a "destination" and the pace is slow enough to look around. Students comment after the experience that they seldom walk across campus without looking at their phones or carrying a heavy backpack and that they rarely walk on campus without a destination in mind. More specifically, we discuss the physical experience (what the ground felt like, coordination of their bodies, what the air was like, whether we passed by architecture or gardens) and spatial (did their eyes focus on near details or far vistas, did they feel the presence of each other as we walked together, notice patterns of sound, or color in relation to their movement through space?) I ask them if any part of the experience altered their pace, what caught their eye, and if they monitor their thoughts or simply experienced silence.

Eventually after 20-30 minutes of walking, I gather them along the edge of the campus lawn along the bluff that overlooks the city. I hand them a sticky label with the words of John Francis, "As you walk look around, assess where you are, reflect on where you have been, and dream of where you are going. Every moment of the present contains the opportunity for change" (Francis 2009, 36). With the previous quote from Francis pasted into their sketchbook/journals, the students find a spot to sit alone and reflect on the experience.

\section{Completing the circle}

\section{Chapple:}

Students in the Buddhism class, in addition to writing a paper on meditation and temples, also craft a ten to twelve page research paper. One might choose to research and write about the role of Buddhism in war, perhaps including citation of the work 
of Thich Nhat Hanh during the time of the Vietnam conflict. Others may have a family member with a sustained practice that they as students want to understand. Some students develop an interest in a particular form of Buddhism or a particular Buddhist philosopher. Topics may include biographical research on the Dalai Lama or the topic of Buddhism and Ecology or the Jātaka Tales or the Heart Sutra or a philosophical topic such as Emptiness and Compassion as expressed in the Bodhicaryāvatāra.

\section{Brucker:}

Visitors to my classes often introduce the role contemplative practice has played in their lives. In the seminar class, these guests have included meditation center directors, scientists engaged with health, neuroscience and physiology, musicians involved in deep listening practices, dancers, and visual artists. Sculptor and performer Glenn Grishkoff is a regular visitor to both the seminar and studio arts courses. Trained as a ceramic artist, Grishkoff is a three-time cancer survivor and a renowned educator and brushmaker. During a two-part workshop, Grishkoff presents the handmade brush as a tool and demonstrates its use as an extension of the hand/arm/body where making the mark is a form of meditation. He begins by showing students examples of sculptural brushes he uses to create his performances. For example, students watch documentation of the performance work "Marking my Life" where in a costume created from canvas patterned with inky brush marks, Grishkoff wields a monumental horsetail brush 4 feet long and loaded with Sumi ink, creating a large circle representing the cycle of life. This work presents the perfect opportunity for introducing students to the concept of the traditional Japanese ensō. An ensō begins in one place and ends with that one line. There is no retracing. Instead of moving quickly, the line is contemplative, slow and fluid.

As preparation for our ensō meditation, participants begin by creating their own unique brush by choosing a piece of bamboo or driftwood from a pile placed in the center of the studio. Grishkoff talks eloquently about his experience collecting the bamboo and wood from natural environments and encourages students to reach for a branch or bamboo that "speaks" to them. Sometimes students bring a stick of their own to use instead of what is provided, and often they incorporate elements such as shells or beads they have collected. The process of constructing their own paintbrush is exciting, and students learn to hollow the endpoint, insert the special hairs from deer or moose pelts and create patterns, symbols or marks by using wood burners and torching the handle. When the brushes are complete and the hair tips are set, we prepare the studio for the meditation. Students are prompted to embrace the wabi-sabi, meaning 'beauty in the imperfect,' of the ensō experience. Together, students form a circle that includes Glenn. Each student kneels or sits cross-legged but upright on their mats with an ink well and large paper in front of them. I lead them through a breathing meditation and Glenn talks about coordinating the breath and the mark when making the stroke.

Once a few minutes have passed and the class seems quiet and ready we prompt them to connect to the breath in an even deeper way. Can they imagine the breath as a circular shape? Can they sense the repetitive movement of the lungs, chest and nostrils as the air circulates? Through this experience they create a fluid, easy movement related to the breath that can extend to the mark. Glenn is the first to make an ensō by beginning the stroke on an audible outbreath and placing the loaded brush on the 
paper. Each student follows one at a time around the circle creating their unique ensō. Students quietly support each other in the process of making their mark. After some time in silent reflection, the ink has dried and we end by gathering into a circle each holding up our own ensō drawing for the group to view.

\section{Ecology and contemplation Chapple:}

The Buddhism course serves as an elective in the Asian and Asian American Studies major and minor programs. Another Engaged Learning class, World Religions and Ecology, fulfills requirements for majors and minors in Environmental Studies. It similarly asks the students to become engaged and involved. The course begins with an introduction to the First Peoples who lived in the Los Angeles basin. From the classroom we walk to the bluff-top native plant garden co-designed with, most likely, descendants of the Tongva, a Shoshone tribe that arrived on the California coast from Wyoming one thousand years ago. The LMU campus provides one of the few acknowledgements of their history, commemorated in the planting of native medicinals and the creation of a circular gathering space overlooking the Pacific Ocean and the Santa Monica Mountains. Down the bluff, the university worked to help create an interpretive center explaining the local marshy topography adjacent to a massive burial site into which Tongva bodies were re-interred after a study by archaeologists to make way for development. Midway between the two, halfway down the 150-foot escarpment, the students discover an artesian well, the source of water for the original settlement known as Su'angna, meaning sweet waters. The site visits, spread over three different days, give students a rich sense of place, a feeling of connection with the local flora and fauna. While we are outdoors, students gaze upon the hovering hawks and share stories about their encounters with raccoons on campus. A relaxation sets in, bringing the students to a place of contemplation.

\section{Brucker:}

I also use the Gabrielino/Tongva Memorial in my course. My students are asked to explore the garden and memorial area adjacent to the LMU student residences where some of them live. Surprisingly, many have not spent time at the site before the visit. A guest biologist accompanies us, and tells us stories of these 'People of the Earth'. We gather clay-like dirt from the site and allow our fingers to leave a 'mark' in our sketchbooks.

We look together out toward the Pacific Ocean and towards the Santa Monica Mountains as did Native Americans who may have stood on this very spot. We talk about water as a resource in an environment that is drought-stricken. Our biologist explains some of the native plants and the ability of the vegetation to adapt to the dryness of the climate. Low stone benches surround a dolphin-motif pavement circle that is, in turn, bordered by explanatory plaques. Students take turns reading the plaques aloud to the group, discovering the history of the native people in the area.

On our latest visit we saw crows and watched them land on a nearby fence and fly together. We then walked to the display cases in a nearby building to view the artifacts of the long-ago residents that were found during construction on the site. We learned about the artifacts and made drawings of them. Returning to the memorial site, we 
could see over the bluff, and look down at the site where the remains of over 200 Native Americans were found on the Playa Vista property below the university. Now developed land, these remains were re-buried in an earthen mound somewhere below. We end the class session with a silent meditation on site.

\section{Ritual}

Brucker:

Another visitor to the seminar course on contemplative arts is Jeremy Hahn, a former student in my beginning drawing course who now has his MFA in dance and incorporates the contemplative into his own movement pedagogy.

Jeremy invites students to participate in contemplative movement practices by activating their perceptions and discovering a "newness" inside each moment of movement. In this sense they embrace their own agency. This agency is expressed through a willingness to participate while consciously making connections kinesthetically, mentally, and emotionally.

Jeremy has worked with the class to introduce improvisational movement as mindful rituals. In this approach, he was inspired by the work of Anna Halprin whose pioneering work in human movement and dance thinks of ritual as actions that are repeated intentionally (Halprin 2012). Students are given the opportunity to focus upon the task at hand, isolating a body part - a shoulder or foot for example, by performing a series of prescribed or repeated movements or tasks without concern for or knowledge of the final outcome.

For example, when students explore dance movement concepts with eyes closed they shift from a state of intellectual analysis and visual processing to a space of sensing and feeling. They must shift their attention from a need to reach a particular end or goal into a process-oriented focus. Dance scholar Melinda Buckwalter describes the practice of improvisational movement as, "the experience of moving and not knowing, finding the next thing, and learning about what is becoming in the process" (Buckwalter 2010, 4). By exploring structured improvisational scores they learn the rules and perimeters that provide a framework for spontaneous movement. In this way, students develop and strengthen their ability to have a kinesthetic dialogue through movement and community.

\section{Chapple:}

For many years, I served as Pujari, or ritual specialist for a small Yoga Ashram on Long Island in New York. Training for this responsibility required a series of meditations over the course of several months, beginning with a twenty-minute focus each morning and evening on a plate of soil, generating an intimacy with the earth element. After a month of this engagement, a second month was devoted to gazing and reflecting upon a clear vessel of water. The third month required twice-daily gazing upon a flame; the fourth, feeling and observing wind and breath; the fifth, sitting perfectly still within the vast expanse of space. Correlatively, during the day, the stuff of the earth would surprise me with its fragrances and flavors and colors and touch and tones. The daily ritual expanded into a feeling of connection with the cosmos, giving texture to the ritual duties of creating and maintaining sacred space.

As part of their learning experience, students in World Religions and Ecology place themselves into five different "interest groups" that correlate to the five elements. Their research 
and service projects correlate to these five areas. For instance, students with a deep interest in the earth and plants are encouraged to either volunteer to work with the gardeners on campus to further improve our impressive gardens of plants native to Southern California. They are also encouraged to volunteer with Tree People, a world-famous organization started in Culver City that seeks to plant and maintain an urban forest. Local gardening provides another option, with possible placements at Holy Nativity Church on 83rd Street and the Emerson Avenue Community Garden, both walking distance from campus. Others work with the on-campus organic vegetable garden where dense kale grows year-round.

Students interested in water are encouraged to get involved with Heal the Bay, the various organizations devoted to the rehabilitation of the campus-adjacent Ballona Wetlands, the Surfrider Foundation, or perhaps the Hyperion Wastewater Treatment Plant in nearby El Segundo.

Transmutations of fire in the form of energy play a vital role in human involvement (and interference) with the world of nature. Those who are interested in the element of fire are encouraged to research the various developing options for solar energy, geo-thermal energy, and electric and hybrid cars. One service project student researched the various companies selling hybrid and electric cars such as Tesla, Coda, Volt, Prius, etc., and created a buyer's guide.

Clean air has been protected for generations in Southern California by the South Coast Air Quality Management District. In light of global climate change, the reduction of greenhouse gases has been touted by politicians and scientists as an important piece of the puzzle. Students are encouraged to discover how California and other states and nations are taking the initiative to reduce $\mathrm{CO} 2$ in the atmosphere.

The final element discussed and studied in class is space. How do urban issues such as zoning, housing, and traffic help or hinder environmental health? How have traditional religious worldviews responded to land usage? Housing size? Students are encouraged to reflect on their own wants and needs and are encouraged to seek out neighborhood associations active in zoning and land use issues.

\section{Linking to LMU's mission: exploring the sacred Brucker:}

Seeing life and the world as a gift calling forth wonder and gratitude is an aspect of deepening spiritual and personal awareness from the Jesuit and Marymount traditions. Incorporating these experiences into the freshman experience happens outside the classroom through various opportunities provided by LMU campus ministry. In the FYSCP course we engage in the practice of Ignatian Imagination.

For this exercise, we meet Fr. Randy Roche, SJ in the intimate Leavey Chapel of Our Lady of Good Hope on campus. This tiny chapel features six stained glass windows dedicated to Mary as the "Mother of Fair Love." Fr. Roche tells us the intriguing history of the windows. Created by two young Hungarian artists Edith and Isabel Piczek, the thick glass and jewel-like forms illuminated by the evening light create imagery that is both figurative and abstract. Edith refers to her lifetime vocation as an artist who visualizes God's work noting that it is through deep study and reflection that she creates.

Fr. Roche introduces the meditation by describing for us the way Ignatian Imagination has played a part in his life. Students reflect on the role that story plays in their lives and he 
in turn asks students to consider how the image in the medieval church was used as a visual storytelling device, where paintings and windows allowed the faithful who could not read Latin to learn the biblical stories. He also explains that the direct experience of being present to the light and imagery of the windows is the essence of generating Ignatian conversar - an intimate conversation that exists between the student and the Divine.

Students then are led by Fr. Roche in a series of reflections. Repeatedly asking, "What do you see?" he helps them to access their intuitive ability to read visual language and interpret for themselves the stories, colors, and forms.

\section{Linking to LMU's mission: learning by doing Chapple:}

LMU's Center for Service and Action helps students earn between fifteen and twenty hours of service with a non-profit organization. Each student affiliates with a non-profit organization that fits their needs and interests. These have included gardening at the Sivananda Yoga Vedanta Center in Marina Del Rey, a certified center for "Green Yoga." At the Benedict Canyon Retreat Center operated by InsightLA in Beverly Hills, students engaged in hands-on ecological restoration, clearing non-native plants to allow chaparral to flourish. At Heal the Bay, students have participated in a moonlight fish count, observing grunion beach themselves at night to spawn. Adjacent to LMU, many students work with the Friends of Ballona Wetlands, cleaning up the local beach at Playa Del Rey and restoring pickleweed and other salt tolerant plants in the marsh. With Tree People, students plant and maintain trees both in rugged canyons and in rugged neighborhoods.

One of the favorite placements has been at Animal Acres Farm Animal Sanctuary in Acton, in the high country of northern Los Angeles County. Students muck the stalls, feed animals, and invariably fall in love with goats. More locally, the LMU Office of Sustainability places students in the LMU Garden: weeding, planting, harvesting the organic produce grown on campus. At the Holy Nativity Church Garden, students prepare produce for delivery to the food bank. At Venice High School's Learning Garden they discover many modalities of soil preparation and cultivation. At Star Eco Station in Culver City future teachers develop lesson plans for nature education. LMU's Center for Urban Resilience (CURES) has involved engaged learners in statistical monitoring of park usage and other projects. The list of possibilities changes each year, and each year enterprising students propose their own projects, forging connections with new partners.

The connection between engagement and contemplation arises organically and naturally with these field placements. Each of the organizations professes a passion for some aspect of the natural world, a connection that arises from love and concern. The students find these experiences captivating and transformative and sometimes choose to enter post-graduation service at one of the many agencies such as Teach for America or the Jesuit Volunteer Corps.

\section{Conclusion}

\section{Brucker:}

"Awareness practice is not just sitting meditation, or meditation-in-action alone. It is a unique training practice in how to behave as an inspired human being. That is what is meant by being an artist" (Trungpa and Judith 2008, 25). 
Aiding students in creating a mental shift to a slower more reflective perception, enables beginning students in drawing class to see as artists and allows students in the freshman seminar to discover a deeper more authentic sense of self. This shift in consciousness is what Trungpa defines as a unique training practice that not only inspires the artist and writer but encourages creativity and changes behavior. Valuing such a shift is not unfamiliar to those steeped in the Jesuit traditions or to those that engage in daily contemplative practice. For students in the midst of their university studies, introducing and validating experience and engagement as a viable source of information and inspiration helps them to develop an attitude of appreciation toward reflection that prepares them for their time at LMU and on the planet.

\section{Chapple:}

Students arrive at any university campus in varied states of mind: enthused, bewildered, competitive, self-assured, and insecure. Some are quite worldly while others have been quite sheltered. Most have fluency in popular culture and navigate the surface of the internet with ease. If they want a fact or if they want to find something to buy or visit, they instantly beckon their phones or tablets into action. In many ways, the job of the professor has changed. No longer do professors possess the keys to find information, to communicate a time line, to define unknown terms in often exotic languages. The job has shifted focus to helping students gain skills of discernment and to provide occasions for them to explore the inner geography of their hitherto largely unknown intellectual and psychic processes and to venture into the geography of their place.

The Buddha and his successors taught effective tools for understanding the human mind. Inviting students to learn techniques of meditation from a live teacher and to engage in community building with other classmates as part of their learning experience perhaps can replicate the human touch that characterized life in the village of old. Buddhist compassion can start with forgiving the tardy classmate, the dense traffic, the uncooperative classroom technology, or the (seemingly) disorganized professor.

Many students have walked by the native oak or sycamore trees on campus without knowing their local history and significance. Bringing students to the local artesian springs and groves and telling the story of the Tongva people and explaining the grass-roots resistance against hyper-development gives them a sense of belonging and connection to place.

The Bodhicharyavatara of Shantideva lauds the vow of the Bodhisattva, through which one puts the needs of others before one's own needs, as found in this verse:

Those desiring speedily to be a refuge for themselves and others should make the interchange of "I" and "other," and thus embrace a sacred mystery (VIII:120)

(Padmakara Translation Group 2008).

The task of the professor in the 21st century holds the promising possibility of inculcating a sense of narrative and purpose that allows emerging adults to become, in the words of Pedro Arrupe, S.J., former Superior General of the Society of Jesus, "men and women for others" (Arrupe 1973). LMU's Engaged Learning, coupled with contemplative practice, serves to inspire such purpose within each of our students. 


\section{Funding}

No funding was used for the production of this article.

\section{Authors' information}

Jane Brucker uses sculptural objects and performance to engage the viewer through contemplation, movement and ritual activity. In works that exhibit a strong tactile sensibility, she is able to simultaneously explore the visceral and the spiritual. Her work has been performed and exhibited at venues throughout the United States and internationally, in Nepal, Germany, Scotland, France, Japan and the Czech Republic. She is a professor at Loyola Marymount University where she incorporates her experience as an artist and a certified teacher of the Alexander Technique into teaching drawing to animators, designers and artists and contemplative practice to freshmen. Her degrees include an MFA from The Claremont Graduate University; a MA in Religion and the Arts, from The Claremont School of Theology. Her fellowships include the Skowhegan School of Sculpture and Painting; Scottish Sculpture Workshop Winter Residency in Darkness and Isolation; DRAWinternational; and Künstlerhaus Schloss Plüschow. She recently contributed her pedagogical insights to a forthcoming book "The Mindful Eye: Contemplative Pedogogies in Visual Arts Education" and is a fellow of the Academy of Catholic Thought and Imagination at Loyola Marymount University.

Christopher Key Chapple is Doshi Professor of Indic and Comparative Theology and Director of the Master of Arts in Yoga Studies at Loyola Marymount University. He has published twenty books and more than 150 articles and chapters on topics that include the religions of India and spiritual aspects of ecological activism. He serves on the advisory boards for the Uberoi Foundation (Denver, Delhi), the Ahimsa Center (Pomona), the Forum on Religion and Ecology (Yale), the International Summer School for Jain Studies (New Delhi), and the Jain Studies Centre of the School for Oriental and African Studies, University of London. He edits the journal Worldviews: Global Religions, Culture, and Ecology (Brill).

\section{Competing interests}

The authors declared that they have no competing interests.

Received: 30 September 2016 Accepted: 10 January 2017

\section{Published online: 13 February 2017}

\section{References}

Arrupe S.J., Pedro. 1973. "Men and Women For Others." http://onlineministries.creighton.edu/CollaborativeMinistry/ men-for-others.html Accessed: 28 Sept 2016

Fischer, Norman. 2013. Training in Compassion: Zen Teachings on the Practice of Lojong. Boston: Shambala. Ozeki, Ruth. 2013. A Tale for the Time Being. New York: Viking.

Padmakara Translation Group. 2008. The Way of the Bodhisattva: The Bodhicharyavatara of Shantideva. Boston: Shambala.

Birkerts, Sven. 2015. Changing the Subject: Art and Attention in the Internet Age. Minneapolis: Graywolf Press. Buckwalter, Melinda. 2010. Composing while Dancing: An Improviser's Companion. Madison: University of Wisconsin Press. Edwards, Betty. 1979. Drawing on the Right Side of the Brain. New York, NY: Tracher.

Francis, John. 2009. Planetwalker: 22 Years of Walking. 17 Years of Silence. Washington, DC: National Geographic.

Francis, John. 2011. The Ragged Edge of Silence: Finding Peace in a Noisy World. Washington, DC: National Geographic. Franck, Frederick. 1973. The Zen of Seeing: Seeing Drawing as Meditation. New York: Vintage.

Goldberg, Natalie. 1986. Writing Down the Bones: Freeing the Writer Within. Boulder: Shambhala Publications.

Halprin, Anna. 2012. Dance as a Way of Life: An Anna Halprin experience. Personal Collection of A. Halprin, Mountain Home Studio, Kentfield CA

Harris. "Rockery Reverie \#3 Stoned Thinking," The Petriverse of Pierre Jardin. https://petriverse.wordpress.com/rockeryreveries/rockery-reverie-3-stoned-thinking/. Accessed 27 Sept 2016

Kabat-Zinn, Jon. 1994. Wherever You Go, There You Are. New York: Hyperion.

Nicolaides, Kimon. 1941. The Natural Way to Draw. Boston: Houghton Mifflin Company.

Trungpa, Chögyam, and Lief L. Judith. 2008. True Perception: The Path of Dharma Art. Boston: Shambhala.

Tedx Tokyo. "John Francis: The Power of Walking and Silence." http://archive.tedxtokyo.com/en/talk/john-francis/. Accessed 2 Dec 2016

Winston, Diana. 2003. Wide Awake: A Buddhist Guide for Teens. New York: TarcherPerigee.

"Bellarmine College of Liberal Arts," Bellarmine College of Liberal Arts Loyola Marymount University, accessed 2 Dec 2016, http://bellarmine.lmu.edu

"LMU Mission Statement," Loyola Marymount University, accessed 2 Dec 2016, http://mission.Imu.edu/missionstatement/ Roche, Randy. 2016. "Ignatian Imaginative Contemplation" personal essay

\section{Further reading}

Mitchell, and Donald. 2002. 2013Buddhism: Introducing the Buddhist Experience. New York: Oxford University Press.

Against the Stream Vipassana, West Hollywood and Santa Monica www.againstthestream.org

Dharma Vijaya Buddhist Vihara; 1847 Crenshaw Blvd.; LosAngeles, CA 90019; 213-737-5084 www.dharmavijaya.org (Sri Lankan Theravāda)

Garden Shartse Thubten Gargye Ling; 3500 E. Fourth Street; Long Beach, California, 90814 562- 621-9865; www.gstdl.org (Tibetan Vajrayāna)

Hsi Lai Monastery and Buddhist Center in Hacienda Heights. Hsi Lai Temple, 3456 Glenmark Drive, Hacienda Heights, California, 91745; 626-961-9697; www.hsilai.org

International Buddhist Meditation Center; 928 S. New Hampshire Ave:; Los Angeles, CA 90006 www.ibmc.info (Vietnamese Zen) Rinzai-ji Zen Center; 2505 Cimarron Street; Los Angeles, CA 90018; 323-732-2263 www.rinzaiji.org (Japanese Zen) InsightLA, 1401 Olympic Boulevard, Santa Monica www.insightla.org 
Soka Gakkai Friendship Center; 5800 Venice Blvd.; Los Angeles, CA 90019; 323-965-0025 http://www.sgi-lafriendshipcenter.org (Japanese; similar to Pure Land)

Venice Hongwanji Buddhist Temple; 12371 Braddock Drive; Culver City, California 90230 (310) 391-4351; http://vhbt.org (Japanese; Pure Land and Zen)

Zen Center of Los Angeles; 923 South Normandie Avenue ; Los Angeles, CA 90006-1301 (213) 387-2351; www.zcla.org (Japanese Zen)

Wat Thai; 8225 Coldwater Canyon Ave; North Hollywood, CA 91605 818-780-4200; www.watthai.com/ (Thai Theravāda)

Submit your manuscript to a SpringerOpen ${ }^{\circ}$ journal and benefit from:

- Convenient online submission

Rigorous peer review

- Immediate publication on acceptance

- Open access: articles freely available online

- High visibility within the field

- Retaining the copyright to your article

Submit your next manuscript at $\gg$ springeropen.com 